\title{
Begünstigung des Partners im Todesfall
}

\author{
Immer wieder wird in der Beratung festgestellt, dass die finanziellen Risiken \\ des Todesfalls gar nicht oder zuwenig abgesichert sind. Es sollte eine der \\ wichtigsten Aufgaben eines Unternehmers sein, den überlebenden Partner \\ bestmöglich zu begünstigen.
}

\section{Martin Brenner}

Treuhänder mit eidg. Fachausweis, dipl. Steuerexperte

\author{
Korrespondenz: \\ Martin Brenner \\ Brenner Treuhand AG \\ FMH Treuhand Services \\ Gewerbestrasse 6 \\ CH-9442 Oberuzwil \\ martin.brenner@fmhtreuhand.ch \\ www.fmhtreuhand.ch
}

\section{Finanzielle Risiken im Todesfall des Partners}

- Die hinterbliebene Ehegattin muss einen hohen Geldbetrag an ihre beiden Kinder auszahlen und deswegen das Eigenheim veräussern;

- die überlebende Konkubinatspartnerin erhält, obwohl in jahrelanger Lebensgemeinschaft mit dem Verstorbenen, kein Geld, da keine Vorkehrungen getroffen wurden;

- der verstorbene Ehemann war Arzt und hatte erst kürzlich eine Praxis übernommen und teuer renoviert/umgebaut. Die überlebende Ehefrau sieht sich vor einem Berg von finanziellen Problemen wie Praxisschulden/Weiterverkauf Praxis, fehlendes Ersatzeinkommen, zu hohe Hypothek auf dem persönlichen Eigenheim.

\section{Gesetzliche Regelung}

\section{Eherecht}

Bevor der Nachlass geteilt wird, muss die güterrechtliche Auseinandersetzung nach Eherecht durchgeführt werden. Der überlebende Ehegatte nimmt sein Eigengut zurück und erhält die Hälfte des gemeinsam erwirtschafteten Vermögens, der Errungenschaft.

\section{Erbrecht}

Erst jetzt, anschliessend an die eherechtliche Teilung, wird der Nachlass bestimmt und nach Erbrecht geteilt. Das Nachlassvermögen setzt sich aus dem Eigengut des Verstorbenen sowie dem anderen hälftigen Teil des erwirtschafteten Vermögens zusammen.
Sind neben dem überlebenden Ehegatten z. B. noch zwei Kinder vorhanden, so erhält der überlebende Gatte die Hälfte und die beiden Kinder je einen Viertel des Nachlasses.

\section{Optimierungsmöglichkeiten}

Durch die Kombination von Ehe- und Erbvertrag kann eine maximale Begünstigung des überlebenden Partners erreicht werden:

- mit Ehevertrag das ganze gemeinsam erwirtschaftete Vermögen, die Errungenschaft, dem überlebenden Partner zuweisen und

- in einem ergänzenden Erbvertrag die Kinder auf den Pflichtteil $-3 / 8$ - setzen und die so freiwerdende Quote - 5/8 - dem verbleibenden Ehegatten vermachen.

Sind Kinder aus früheren Ehen vorhanden, so müssen immer mindestens die Pflichtteile für diese eingehalten werden.

Weiter ist möglich:

- jeder Partner erstellt ein Testament und setzt darin die Kinder auf den Pflichtteil;

- Erbvertrag mit freiwilligem Erbverzicht von einzelnen Beteiligten;

- Wahl Gütergemeinschaft, falls sehr viel Eigengut sowie keine Kinder vorhanden;

- zusätzliche Absicherung des Ehegatten durch Produkte im Bereich des BVG (berufliche Vorsorge), der Säule 3a oder der Säule 3b.

\section{Fazit}

Durch verschiedene Massnahmen kann eine für den überlebenden Ehegatten optimale Absicherung erreicht werden. 